$$
\text { HFREIVED }
$$

AUG 031999

OSTI

\section{Evaluation of Fluorine-Trapping Agents for Use During Storage of the MSRE Fuel Salt}

D. F. Williams

J. Brynestad
OAK RIDGE

NATIONAL

LABORATORY
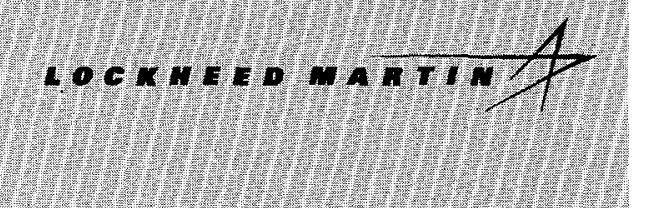

\section{(y)}
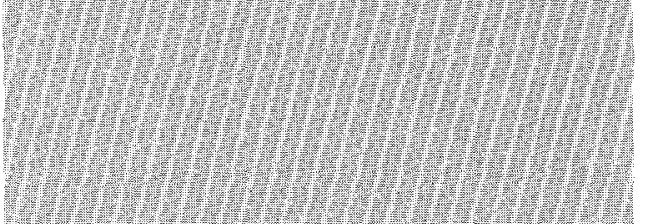

y)

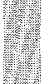

ע

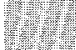


This report has been reproduced from the best available copy.

Reports are available to the public from the following source.

National Technical Information Service

5285 Port Royal Road

Springfield, VA 22161

Telephone 703-605-6000 (1-800-553-6847)

TDD 703-487-4639

Fax 703-605-6900

E-mail orders@ ntis.fedworld.gov

Web site http://www.ntis.gov/ordering.htm

Reports are available to U.S. Department of Energy (DOE) employees, DOE contractors, Energy

Technology Data Exchange (ETDE) representatives, and International Nuclear Information System (INIS) representatives from the following source.

Office of Scientific and Technical Information

P.O. Box 62

Oak Ridge, TN 37831

Telephone 423-576-8401

Fax 423-576-5728

E-mail reports @adonis.osti.gov

Web site http://www.osti.gov/products/sources.html

Reports produced after January 1, 1996, are generally available via the DOE Information Bridge.

Web site http://www.doe.gov/bridge 


\section{DISCLAIMER}

This report was prepared as an account of work sponsored by an agency of the United States Government. Neither the United States Government nor any agency thereof, nor any of their employees, make any warranty, express or implied, or assumes any legal liability or responsibility for the accuracy, completeness, or usefulness of any information; apparatus, product, or process disclosed, or represents that its use would not infringe privately owned rights. Reference herein to any specific commercial product, process, or service by trade name, trademark, manufacturer, or otherwise does not necessarily constitute or imply its endorsement, recommendation, or favoring by the United States Government or any agency thereof. The views and opinions of authors expressed herein do not necessarily state or reflect those of the United States Government or any agency thereof. 


\section{DISCLAIMER}

Portions of this document may be illegible in electronic image products. Images are produced from the best available original document. 
Chemical Technology Division

EVALUATION OF FLUORINE-TRAPPING AGENTS

FOR USE DURING STORAGE OF THE MSRE FUEL SALT

\author{
D. F. Williams
}

J. Brynestad*

*Consultant: AIMS, Inc., 575 Oak Ridge Turnpike, Suite B-3, Oak Ridge, TN 37830.

Date Published - May 1999

Prepared for the MSRE Remediation Project

Bechtel Jacobs Company LLC

Oak Ridge, Tennessee 37831

under contract DE-AC05-98OR22700

Prepared by the

OAK RIDGE NATIONAL LABORATORY

Oak Ridge, Tennessee 37831-6285

managed by

LOCKHEED MARTIN ENERGY RESEARCH CORP.

for the

U.S. DEPARTMENT OF ENERGY

under contract DE-AC05-96OR22464 


.

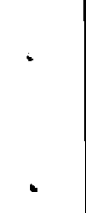




\section{CONTENTS}

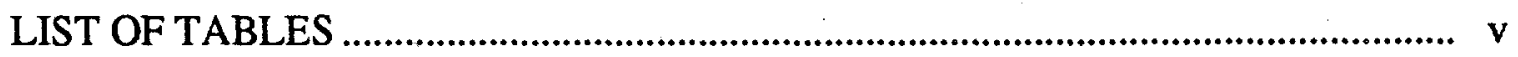

LIST OF FIGURES ….................................................................................... vii

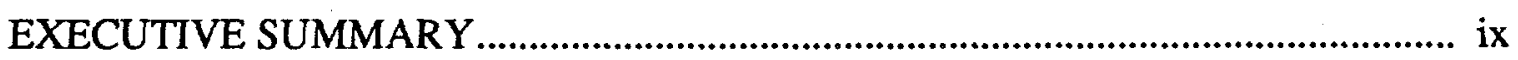

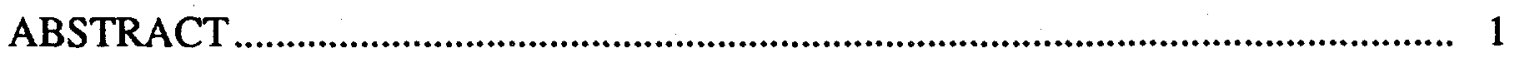

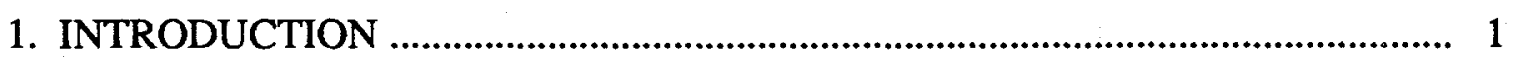

2. FLUORINE TRAPPING REQUIREMENTS …............................................. 3

3. EXPERIMENTAL

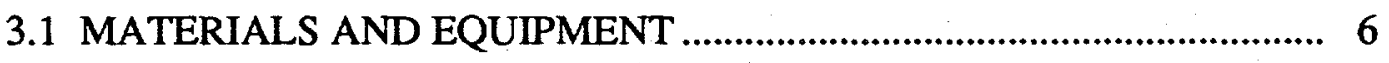

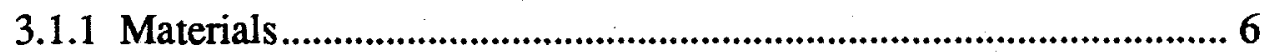

3.1.2 Equipment ................................................................................... 7

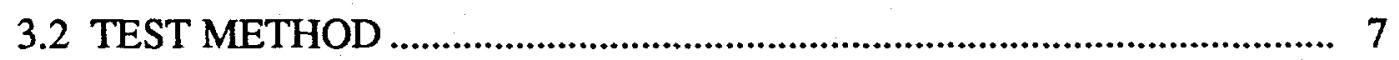

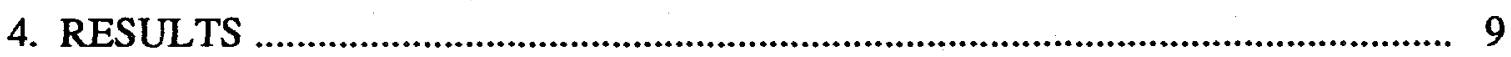

4.1 MOST PROMISING CANDIDATES ……....................................... 9

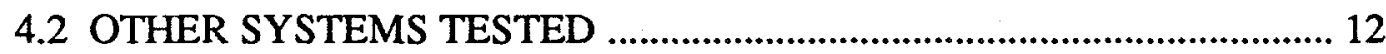

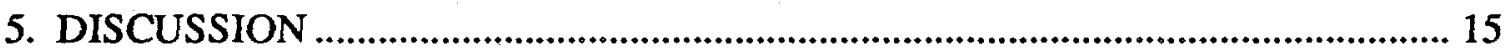

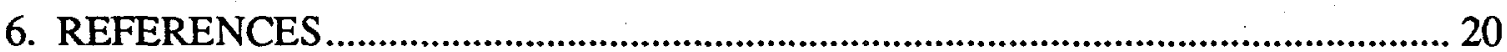




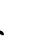




\section{LIST OF TABLES}

Table

Page

1 Dominant energy sources for the fluorinated MSRE salts............................. 4

2 Estimate of radiolytic fluorine generation .................................................... 5

3 Trapping-agent materials ........................................................................ 6

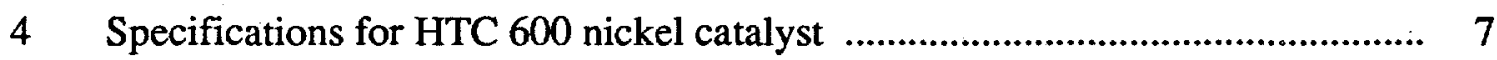

5 Trapping-agent requirements for interim storage and long-term disposal of the MSRE fuel salt: $16.6 \%$ basis................................................................ 15

6 Important characteristics of fluorine trapping agents ............................... 16 


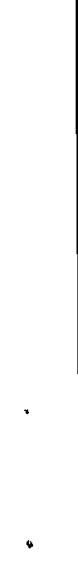




\section{LIST OF FIGURES}

Figure

Page

1 Fluorine production from radiolysis of the fluorinated fuel and flush salts........ 4

2 Experimental apparatus for measuring gas accumulation during $F_{2}$ trapping. 8

3 Fluorine-trapping results for standard activated catalyst ............................... 10

4 Fluorine-trapping results for untreated catalyst and catalyst treated at $500^{\circ} \mathrm{C}$ 10

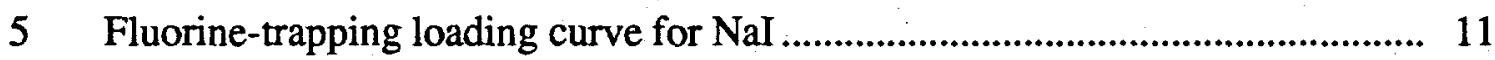

$6 \quad$ Fluorine-trapping pressure history for $\mathrm{NaI}$................................................. 12

$7 \quad$ Fluorine-trapping pressure history for $\mathrm{KI}$........................................................ 13

$8 \quad$ Fluorine-trapping pressure history for $\mathrm{FeSb}$.................................................... 14

9 Fluorine-trapping pressure history for sulfide salts ............................................. 14

10 Basic trapping configurations ...................................................................... 19 


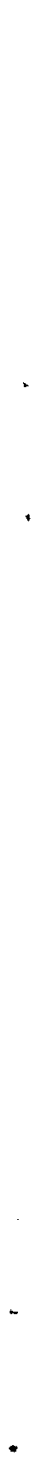




\section{EXECUTIVE SUMMARY}

A fundamental characteristic of the room temperature Molten Salt Reactor Experiment (MSRE) fuel is that the radiation from the retained fission products and actinides interacts with this fluoride salt to produce fluorine gas. The purpose of this investigation was to identify fluorine-trapping materials for the MSRE fuel salt that can meet both the requirement of interim storage in a sealed (gastight) container and the vented condition required for disposal at the Waste Isolation Pilot Plant (WIPP). Sealed containers will be needed for interim storage because of the large radon source that remains even in fuel salt stripped of its uranium content. An experimental program was undertaken to identify the most promising candidates for efficient trapping of the radiolytic fluorine generated by the MSRE fuel salt. Because of the desire to avoid pressurizing the closed storage containers, an agent that traps fluorine without the generation of gaseous products was sought.

Of the materials considered, only activated carbon (i.e., "charcoal"), high-surfacearea metallic catalyst, and sodium iodide exhibited efficient trapping of fluorine gas at room temperature without significant generation of gaseous products. Each of these three materials has advantages and disadvantages for use as a fluorine trapping agent during the storage of the MSRE fuel salt. The most critical factors for each material are described in the following paragraphs.

- At room temperature, charcoal and fluorine form an intermediate carbon fluoride $\left(\mathrm{C}_{2.6} \mathrm{~F}\right)$, which can deflagrate (upon heating to $>100^{\circ} \mathrm{C}$ ) with substantial energy release and pressure generation and can support further combustion in air. Because of this potential for near-explosive behavior, disposal of fluorine on charcoal was discontinued in the 1950s. In the present application, no means of initiating a deflagration event were readily apparent; however, this potential must be acknowledged in any safety analysis associated with storage or disposal of the MSRE fuel sait.

- High-surface-area metallic catalyst reacts with fluorine to form a very stable metal-fluoride product; however, this reagent is both air sensitive and pyrophoric and must be handled or prepared in an inert atmosphere. Eventual venting of the salt canisters before long-term storage must also be accomplished in a controlled fashion. The alumina substrate provides adequate additional fluorine trapping capacity in the vented mode and exchanges oxygen for fluorine. This material loses its "metallic" trapping activity when heated above $300^{\circ} \mathrm{C}$ due to sintering of 
the high-surface-area metal; therefore, special precautions must be taken if this agent is to be introduced into the storage vessel before the molten salt is introduced.

- Sodium iodide ( $\mathrm{NaI})$ is a stable, easily dehydrated salt that efficiently exchanges iodine for fluorine; thus, only the minute vapor pressure of $\mathrm{I}_{2}(\mathrm{~s})$ can exist in a closed storage container with this trapping agent. Because no net loss of trapping activity is measured upon exposure of $\mathrm{NaI}$ to $500^{\circ} \mathrm{C}$, it can be integrated into the storage vessel before the molten salt is introduced. If the fate of iodine during disposal is an issue, the venting system can be configured with an iodine trapping agent; or the iodine can be isolated (or removed), and a conventional fluorine trapping agent (e.g., alumina) can be utilized for the vented operations. 


\title{
EVALUATION OF FLUORINE-TRAPPING AGENTS FOR USE DURING STORAGE OF THE MSRE FUEL SALT
}

\author{
D. F. Williams \\ J. Brynestad
}

\begin{abstract}
An experimental program was undertaken to identify the most promising candidates for efficient trapping of the radiolytic fluorine generated by the MSRE fuel salt. Because of the need to avoid pressurizing the closed storage containers, an agent that traps fluorine without the generation of gaseous products was sought. In addition to the previously identified nongassing agent (activated carbon), a nickel catalyst (HTC 600) and sodium iodide were found to provide the best trapping performance. An assessment of each candidate for the intended application is given. Results for the less successful materials tested are also documented.
\end{abstract}

\section{INTRODUCTION}

The purpose of this investigation was to identify fluorine-trapping materials for the Molten Salt Reactor Experiment (MSRE) fuel salt that can meet both the requirement of interim storage in a sealed (gastight) container and the vented condition required for disposal at the Waste Isolation Pilot Plant (WIPP). Sealed containers will be needed for interim storage because of the large radon source that remains even in fuel salt stripped of its uranium content. Because of the significant radiolytic fluorine generation of the fuel salt, the need to have compact packages at WIPP, and the desire to use simple salt containers (i.e., to avoid pressure vessel requirements), an effort was made to identify non-gas-generating fluorine-trapping options. The indeterminate interim period of sealed storage also argues for a fail-safe trapping agent that cannot generate high pressures and will maintain a low fluorine inventory.

It should be recognized that the requirement that no net gas generation occur during fluorine trapping is unusual, and it precludes use of the typical oxide materials (e.g., alumina, soda lime) utilized for dry-trapping. Of the commonly used trapping materials, only charcoal binds fluorine without generating a gaseous product; however, the practice of using charcoal for this purpose was discontinued in the 1950 s because of safety concerns [1]. The chemistry that occurs during charcoal fluorination has recently been 
established [2]; therefore, no additional experimental work is necessary in this area. Appropriate charcoal fluorination sources are referenced when comparisons are needed, and safety concerns associated with this option are addressed in Sect. 5.

Fluorine gas is so intensely reactive that it is natural to suppose that many materials trap fluorine without generating gaseous products. In the scientific literature, many "unheated" materials are reported to burn spontaneously and to completion in fluorine, while generating no gaseous products. These reports are somewhat misleading because (a) the thermal initiation of "burning" is a critical step, and (b) the local heat of reaction must be sufficiently intense to uncover new material for further reaction. In a situation where less-concentrated fluorine is contacted with a substrate, a protective fluoride layer often forms and inhibits further reaction ("passivation"). The slow, steady generation of fluorine by the fuel salt corresponds more closely to the passivation regime; therefore, we expect no local "hot spots" to drive the fluorination reaction beyond what we observe at roomtemperature conditions. The term "getter" is often applied to materials that scavenge species and do not rely on high local reaction rates. We require a trapping agent that functions as an efficient getter. For situations where conventional oxide-containing trapping materials are challenged with dilute fluorine streams that do not generate a hot reaction front, it is common to heat the traps to improve their efficiency [3].

The most obvious strategy for identifying potential trapping agents is to use extremely high-surface-area materials that are not prone to passivation. Metallic catalysts appear to be the most promising candidates for this purpose. Because these materials are usually built on an oxide substrate, the influence of the substrate must also be accounted for. After extensive discussions with commercial suppliers of catalysts, a nickel-based catalyst was selected to screen this option. Another strategy is to identify materials that do not form an adherent fluoride film; instead, the reaction acts to uncover new surface and to propagate the trapping process. We know that most of the common transition metals (i.e., those in the middle of the periodic chart) readily passivate at room temperature [1]. There is some indication in the literature [4-6] that the less common metals on the left- and right-hand sides of the chart do not readily passivate. After screening these "reactive" metals based on their suitability (need for high melting point, low toxicity) calcium- and antimony-containing metals were selected as candidate materials.

Certain salts may react with fluorine to completion without generating significant gaseous products. The iodides and sulfides appear to be the most promising candidates for this strategy $[7,8]$ because of their potential for forming gaseous intermediates that 
uncover new substrate and continue to react, thus propagating the trapping process without a net generation of gaseous product. A number of sulfides and iodides were selected to explore this strategy. Sections 2-4 document not only the materials, methods, and results, but also provide the basis for the fluorine trapping requirements. Section 5 organizes the experimental results in the form of a comparison of the most promising candidates, with special emphasis on implementing the trapping option with a particular material.

\section{FLUORINE TRAPPING REQUIREMENTS}

The decay energy associated with the MSRE fuel salt causes radiolysis of the salt and the eventual liberation of fluorine gas. Our best estimate of the yield is that two molecules of fluorine gas are released for every $10,000 \mathrm{eV}$ of deposited energy ( $G=0.02$ molecule $\mathrm{F}_{2} / 100 \mathrm{eV}$ absorbed dose). This estimate has been verified $( \pm 50 \%)$ in a number of experiments involving beta-gamma radiation and is consistent with the radiolytic fluorine inventory now identified with the MSRE [9]. This yield value has been provisionally adopted for alpha-decay energy, even though radiolysis of the salt by this mode has never been observed. The widespread belief is that alpha radiolysis is less effective in this instance because the shorter energy deposition track associated with alpha particles promotes recombination of fluorine and the metal sites in the salt. It has also been established that there is a damage limit beyond which fluorine is not liberated. This asymptote occurs after $2 \%$ of the fluorine has been driven from the salt $(0.35 \mathrm{mmol}$ $\mathrm{F}_{2}$ liberated per gram of salt) for the $20-80 \mathrm{MR} / \mathrm{h}$ dose rate of a cooling HFIR fuel element [10]. The damage limit for the less intense field of the MSRE fuel salt will be less than this value.

The energy deposited in the salt during interim storage is readily estimated by using the inventory compiled in ORNL/TM-13142 [9] and standard handbook information. The significant isotopic sources are summarized in Table 1, and the resulting fluorine production is reported in Fig. 1. It is assumed that uranium isotopes are present at the upper level set by the fuel salt fluorination specification $(50 \mathrm{ppm}$, total uranium). Figure 1 and Table 2 show the prediction that the $2 \%$ damage limit $(1630 \mathrm{~mol} \mathrm{~F})$ is reached after 13,000 years of storage and that an interim storage period of 20 years will result in an accumulation of $\sim 85 \mathrm{~mol}$ of fluorine. Results for the MSRE flush salt, which are also included in Table 2 and Fig. 1, reveal that an insignificant amount of fluorine is generated by the flush salt during the interim storage phase, but that a damage-limit trapping capacity will eventually be required for long-term disposal. The most likely 
Table 1. Dominant energy sources for the fluorinated MSRE salts

\begin{tabular}{lcccc}
\hline & \multicolumn{2}{c}{ Initial activity $^{a}(\mathrm{Ci})$} & \multicolumn{2}{c}{$\begin{array}{c}\text { Decay energy } \\
\text { (MeV per }\end{array}$} \\
\cline { 2 - 3 } Decay source & Fuel salt & Flush salt & disintegration $)$ & Half-life (y) \\
\hline${ }^{90} \mathrm{Sr} / \mathrm{Y}$ & 6700 & 114 & 1.132 & 28.5 \\
${ }^{137} \mathrm{Cs} / \mathrm{Ba}$ & 5600 & 95 & 0.816 & 30 \\
${ }^{151} \mathrm{Sm}$ & 117 & 2.0 & 0.125 & 90 \\
${ }^{239} \mathrm{Pu}$ & 41.7 & 0.79 & 5.10 & 24,110 \\
${ }^{240} \mathrm{Pu}$ & 15.3 & 0.14 & 5.16 & 6540 \\
${ }^{241} \mathrm{Am}^{b}$ & 30 & 0.54 & 5.5 & 433 \\
${ }^{233} \mathrm{U}+$ chain $^{c}$ & 1.9 & 0.88 & 38.3 & 159,000 \\
${ }^{228} \mathrm{Th}+$ chain $^{2}$ & 132 & 0.84 & 34.3 & 1.9 \\
\hline
\end{tabular}

${ }^{a}$ Starting reference is the year 2000 .

${ }^{b}$ The effect of ${ }^{241} \mathrm{Pu}$ is lumped into this bounding level of ${ }^{241} \mathrm{Am}$.

${ }^{c}$ Assumed to be present at the 50-ppm level set as the upper bound for the fluorination endpoint.

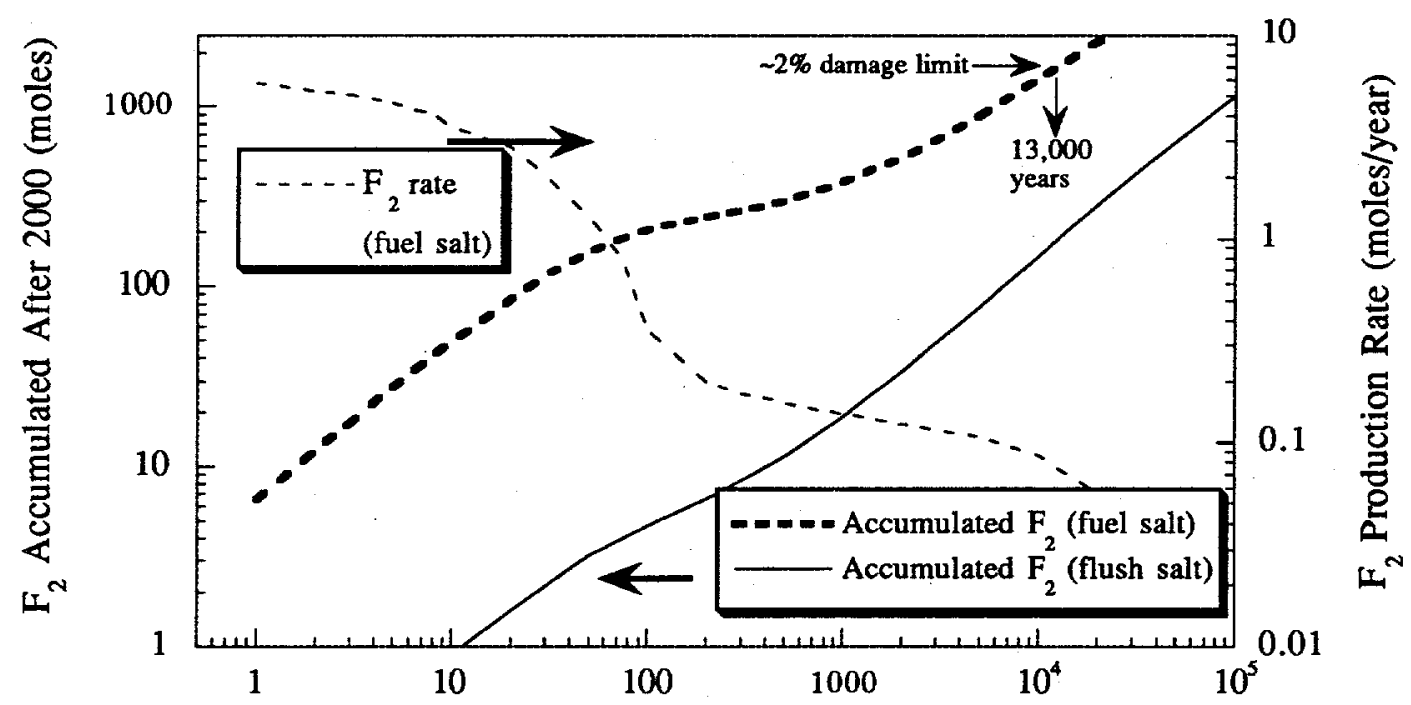

Elapsed Time After 2000 (years)

Fig. 1. Fluorine production from radiolysis of the fluorinated fuel and flush salts. 
Table 2. Estimate of radiolytic fluorine generation

\begin{tabular}{ccc}
\hline Decay period (y) & $\begin{array}{c}\text { Fuel salt }^{a} \\
\text { (total mol F }\end{array}$ & $\begin{array}{c}\text { Flush salt }^{a} \\
\text { (total mol F }\end{array}$ ) \\
\hline 1 & 6.4 & 0.1 \\
2 & 12.2 & 0.2 \\
4 & 22.6 & 0.4 \\
6 & 32.0 & 0.6 \\
8 & 40.7 & 0.7 \\
10 & 48.9 & 0.9 \\
20 & 84.2 & 1.6 \\
50 & 153 & 3.2 \\
100 & 205 & 4.7 \\
200 & 241 & 6.6 \\
500 & 296 & 11.3 \\
1000 & 374 & 18.9 \\
2000 & 514 & 33.8 \\
5000 & 886 & 77.5 \\
10000 & 1425 & 148.0 \\
13000 & 1630 (damage limit) & 189.1 \\
\hline
\end{tabular}

${ }^{a}$ Values derived from integration of decay sources in Table 1 and a yield value of $G=0.02$ molecule/100 eV.

packaging option [11] is that the fluorine load of the fuel salt will be spread between six containers. Each package is now projected to have an $87-\mathrm{L}$ void space in the tank. The following conditions appear self-evident and are derived from an internal assessment of the packaging requirements [12]:

- The packaging system shall include a getter to react with the fluorine gas that is generated by radiolysis of the salt during storage.

- The quantity of getter shall prevent the overpressurization of the canisters during the interim storage period when the canisters are hermetically sealed.

- The design shall include provisions that hermetically seal the canister during interim storage periods but permit the canister to be vented through a HEPA filter when placed in an overpack for transport and final disposal.

Based on these requirements and the previous calculations, it appears that $85 \mathrm{~mol}$ of $\mathrm{F}_{2}$ must be trapped by a non-gas-generating "getter" material (20-y basis), and that a total trapping capacity of $1630 \mathrm{~mol} \mathrm{~F}_{2}$ must be provided. 


\section{EXPERIMENTAL}

\subsection{MATERIALS AND EQUIPMENT}

\subsubsection{Materials}

The materials for this work consisted of a reactive gas (fluorine), an inert carrier/blanket gas (helium), a reducing gas $\left(4 \% \mathrm{H}_{2} / \mathrm{Ar}\right)$, and the various solid trapping agents. The fluorine gas was research grade ( $>97 \%$ pure, Air Products and Chemicals), and both the helium and $4 \% \mathrm{H}_{2} /$ Ar were ultrahigh-purity grade $(>99.99 \%$ pure, Air Liquide America Corp.). Except for the nickel catalyst, all of the trapping materials were high-purity laboratory reagents and were ground (if necessary) to pass through a 325mesh screen, and then dried in a vacuum oven (or reaction chamber) at $145^{\circ} \mathrm{C}$ to remove moisture. Reagent purities and sources are listed in Table 3.

Table 3. Trapping-agent materials

\begin{tabular}{llc}
\hline \multicolumn{1}{c}{ Material } & \multicolumn{1}{c}{ Source } & Purity (\%) \\
\hline Calcium metal $(\mathrm{Ca})$ & Alfa Aesar & $>99.5$ \\
Antimony metal $(\mathrm{Sb})$ & Baker Analyzed & $>99.9$ \\
Iron antimonide $(\mathrm{FeSb})$ & Cerac (I-1023) & $>99.5$ \\
Calcium sulfide $(\mathrm{CaS})$ & Alfa Aesar & $>99.95$ \\
Sodium sulfide $\left(\mathrm{Na}{ }_{2} \mathrm{~S}\right)$ & Alfa Aesar (\#1321) & $>99.95$ \\
Zinc sulfide $(\mathrm{ZnS})$ & Alfa Aesar (\#88299) & $>99.9$ \\
Nickel sulfide $(\mathrm{NiS})$ & Alfa Aesar (\#35661) & $>99.9$ \\
Potassium iodide $(\mathrm{KI})$ & Alfa Aesar(\#87627) & $>99.99$ \\
Sodium iodide $(\mathrm{NaI})$ & Mallinckrodt & $>99.9$ \\
HTC 600 nickel catalyst & ICl/Crosfield, Ltd./UK & \\
& (ICl/Synetix USA) & \\
\hline
\end{tabular}

The HTC 600 catalyst is a high-surface-area engineered pellet, and therefore was not ground; however, this material had to be activated to convert it from the (as-received) passivated oxide form to the active metal form. Activation was achieved by modifying the manufacturer's instructions to account for reduction with $4 \% \mathrm{H}_{2} / \mathrm{Ar}$ rather than the more concentrated hydrogen streams specified by the manufacturer. The catalyst was heated to $275^{\circ} \mathrm{C}$ for $3 \mathrm{~h}$ or more in a stream of $4 \% \mathrm{H}_{2} / \mathrm{Ar}$ and typically experienced a $3.7 \%$ weight loss after this treatment. Following the reduction step (which is usually performed in the reaction chamber), the material was handled in an inert atmosphere prior to use in the fluorine-trapping trial. Relevant portions of the manufacturer's specifications for the HTC 600 catalyst are given in Table 4 . 
Table 4. Specifications for HTC 600 nickel catalyst ${ }^{a}$

\begin{tabular}{ll}
\hline Nickel content & $26.1 \mathrm{wt} \%$ \\
Packed bulk density & $0.81 \mathrm{~g} / \mathrm{mL}$ \\
Nickel surface area & $143 \mathrm{~m}^{2} / \mathrm{g} \mathrm{Ni}$ \\
Total BET surface area & $200 \mathrm{~m}^{2} / \mathrm{g}$ catalyst \\
Catalyst form & Cylindrical; $1.2-\mathrm{mm}$ trilobe extrudate \\
& $(1.33 \mathrm{~mm}$ OD x $3.7 \mathrm{~mm}$ long) \\
Pore volume & $0.48 \mathrm{~mL} / \mathrm{g}$ \\
\hline
\end{tabular}
Terrace, IL.

${ }^{a}$ Manufacturer: ICI/Crosfield, Ltd., Warrington, England; supplier: ICI/Synetix USA, Oakbrook

\subsubsection{Equipment}

The experimental apparatus consisted of (a) a mass-flow controller for regulating fluorine flow, (b) an electronic transducer for measuring chamber pressure, and (c) a 400$\mathrm{mL}$ gastight reaction chamber. These elements were assembled as shown in Fig. 2. The reaction chamber was a simple cylindrical stainless steel vessel (6-in. length of 2-in. sched. 40 pipe) with a welded flat bottom and a standard conflat-flange top closure. The knife-edge surface of the conflat flange sealed upon a flat copper gasket. Through this top flange, tubing penetrations for the gas inlet and outlet and a compression fitting for a 1/8-in.-OD type $\mathrm{K}$ thermomcouple, were added. All of the isolation valves depicted in Fig. 2 are Monel bellows-seal valves (Nupro M-4BRG) that provide for virtually leakfree containment. All other fittings and piping were of either Monel or stainless steel construction. Temperature and pressure signals were displayed on local readouts and were logged using a simple DOS-based personal computer program.

\subsection{TEST METHOD}

The preliminary steps of each test consisted of loading the trapping agent into the reaction chamber (in an inert-atmosphere box for air- or moisture-sensitive materials that were not activated in place), conditioning or reconditioning of the trapping material if necessary (by heat and vacuum to dry, or hydrogen to reduce), pumping down the chamber to ensure that the system is gastight, and finally, backfilling the chamber with helium to the desired initial test pressure (300-700 torr). Preliminary conditioning of materials was conducted in the early tests to obtain characteristic weight loss data. Most of the later preparations were conducted in place (in the reaction chamber). The test was begun by closing the outlet isolation valve, opening the feed valve, and rapidly ramping the mass-flow controller up to the desired fluorine flow rate. Previous packed-bed experience with HTC 600 catalyst showed that fluorine flows of $5 \mathrm{sccm}$ would produce a 


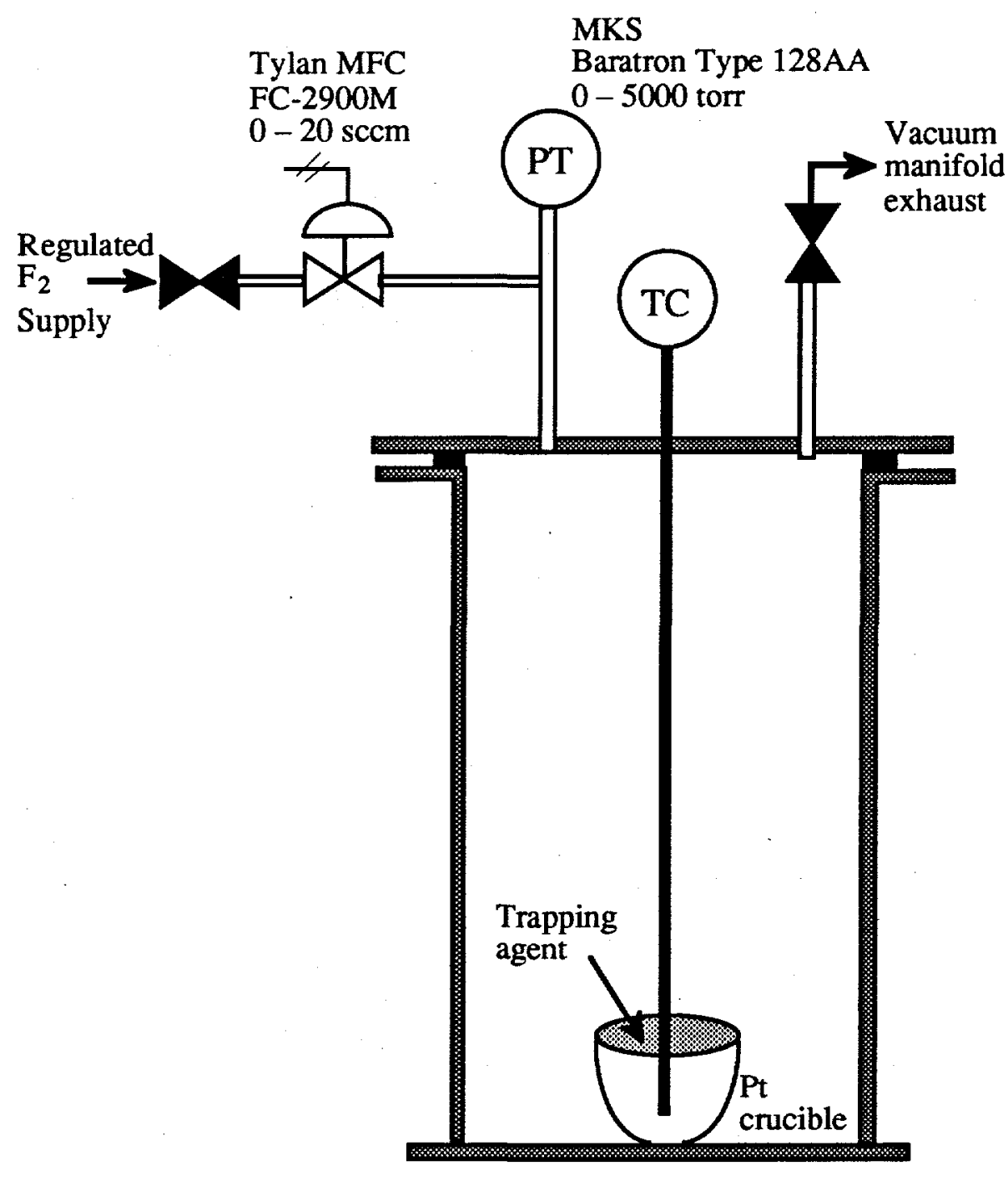

Fig. 2. Experimental apparatus for measuring gas accumulation during $F_{2}$ trapping.

local bed temperature rise in a 1-in. ID column of only $10^{\circ} \mathrm{C}$. Therefore, this flow was set as the upper limit because our objective was to test the "slow-trapping" regime, which is not accelerated by local heating. Temperature rises in the reaction chamber did not register more than $8^{\circ} \mathrm{C}$, and were typically much less. Tests at two widely different fluorine flows were also conducted to confirm that our results corresponded to those of the slow-trapping regime. All of these fluorine fluxes were higher than those expected during storage of the fuel salt. 


\section{RESULTS}

\subsection{MOST PROMISING CANDIDATES}

HTC 600 catalyst and NaI were judged to be the most successful candidates because they rapidly and efficiently trapped fluorine at the low fluorine fluxes expected during salt storage. The reaction of fluorine with the nickel catalyst and its alumina substrate is simpler than that of fluorine with sodium iodide and will be discussed first. Four trials were conducted with the nickel catalyst: a "slow-flow" trial, a "fast-flow" trial, a trial with untreated catalyst, and a trial with activated catalyst exposed to high temperatures $\left(500^{\circ} \mathrm{C}\right.$ ). The slow-flow and fast-flow trials (Fig. 3) were conducted with catalyst prepared by our standardized procedure and were designed to establish the nongassing and the gas-generating trapping capacities, as well as to confirm the absence of a temperature or fluorine-flow rate effect for these trials. The test with untreated catalyst and the test with activated catalyst exposed to $500^{\circ} \mathrm{C}$ in an inert atmosphere (Fig. 4) were conducted to determine whether exposure to air or high temperatures could be tolerated.

In all of the trials, the increase in pressure with time quantifies catalyst behavior and indicates the basic reaction chemistry. For tests with material from a standard regeneration (slow-flow and fast-flow trials), a reproducible nongassing capacity was measured, regardless of the rate of fluorine flow. This value, $0.075 \mathrm{~g} \mathrm{~F}_{2} / \mathrm{g}$ catalyst, is represented by the horizontal portion of the pressure trace in Fig. 3. Catalyst weight gains agreed with this level of fluorine consumption. The initial (transient) rise in pressure associated with the fast-flow test in Fig. 3 reflects the steady-state level of fluorine associated with this rate of uptake. Interruption of the fluorine flow in this initial nongassing regime always returned the pressure to its initial value. For the slow-flow trial, this initial rise in pressure was so small that it was not measurable. It should be noted that for the fast-flow test, the measured catalyst temperature rise was $8^{\circ} \mathrm{C}$; for the slow-flow trial, it was less than $1^{\circ} \mathrm{C}$.

Another feature that should be noted is the capacity associated with the increasingpressure portion of the curve. The rate of pressure rise was much less than that associated with pure fluorine (i.e., maximum slope indicated) and reflects the reaction of fluorine with the alumina substrate (thus releasing $1 / 2 \mathrm{~mol} \mathrm{O}_{2}$ per mole of $\mathrm{F}_{2}$ consumed), as well as the reaction of some nickel. Halting the fluorine flow caused the container pressure to decrease to the level associated with oxygen evolution. The virtual absence of fluorine in this accumulated gas was verified by mass spectrometer measurements. These trials were 


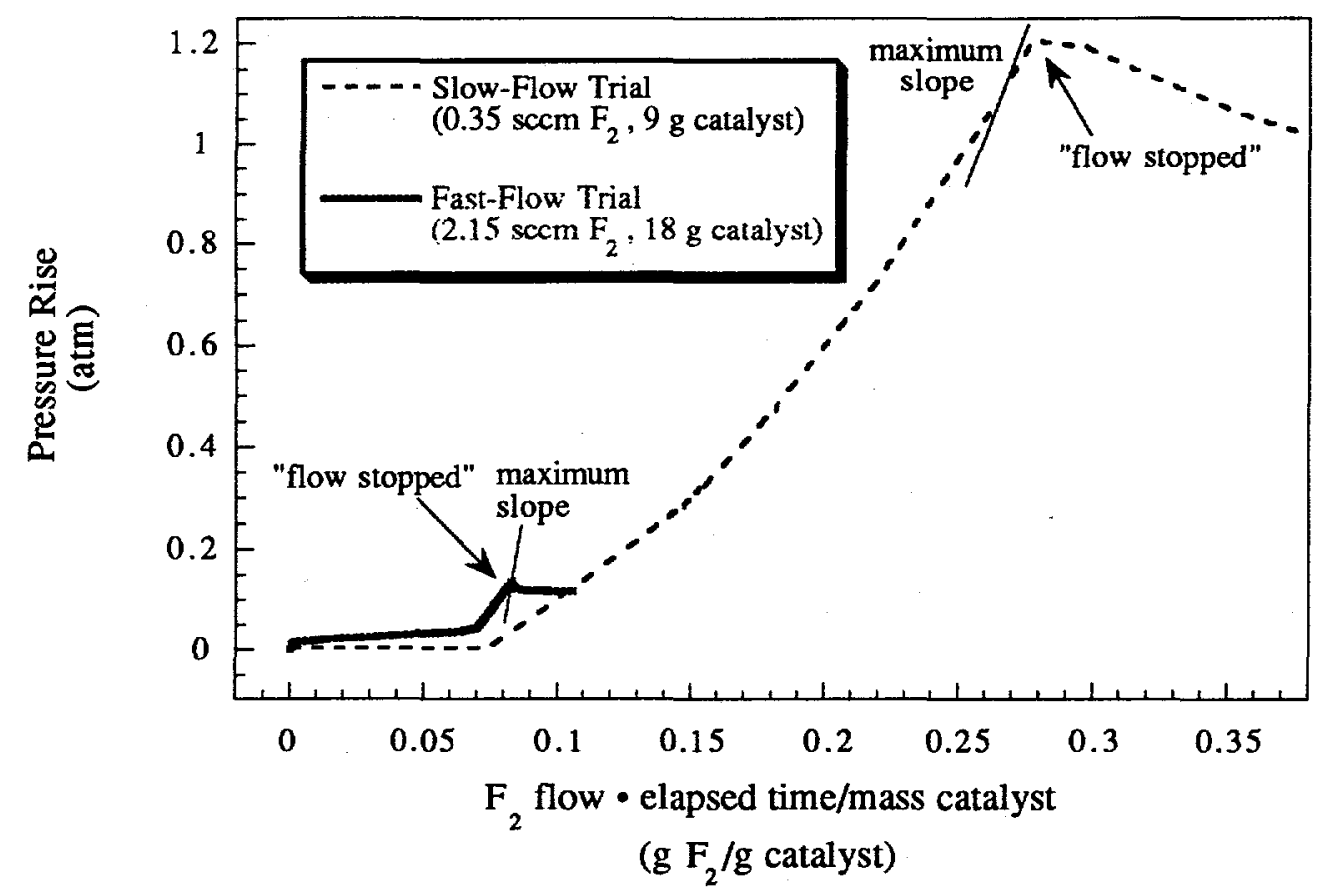

Fig. 3. Fluorine-trapping results for standard activated catalyst.

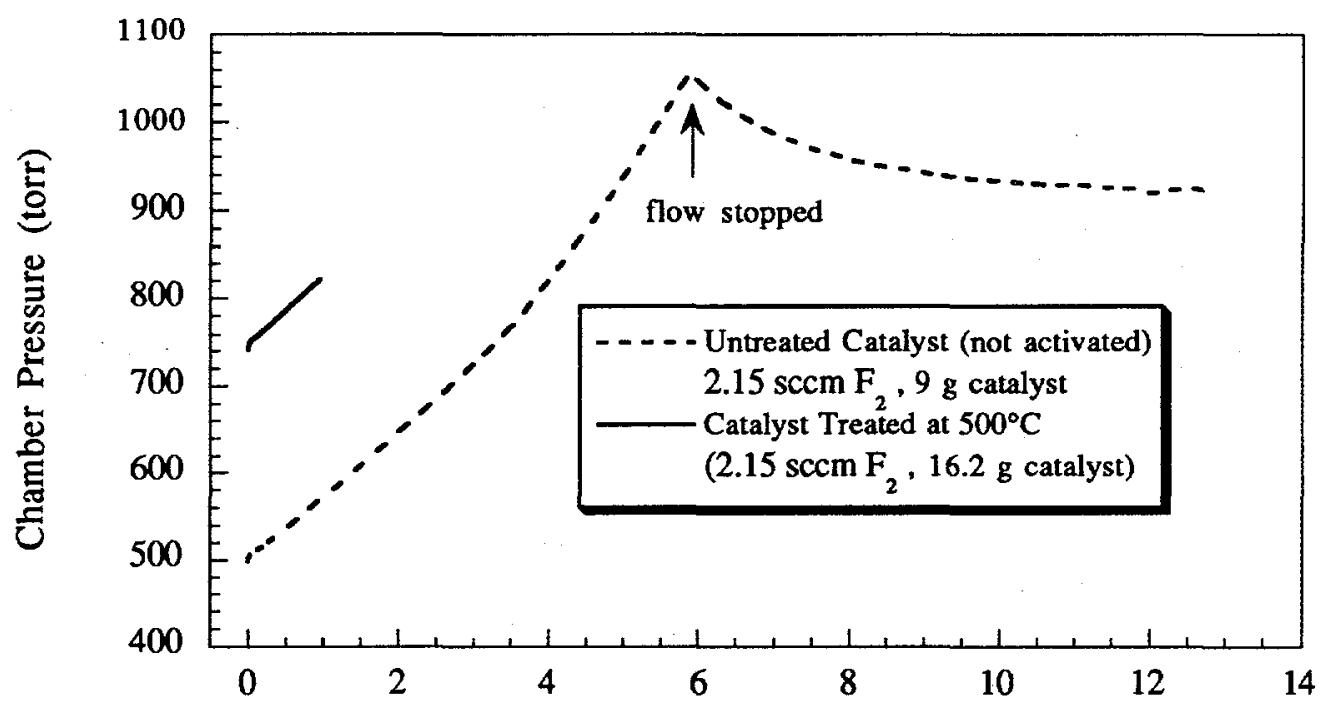

Elapsed Time (h)

Fig. 4. Fluorine-trapping results for untreated catalyst and catalyst treated at $500^{\circ} \mathrm{C}$. 
not carried out long enough to completely react the substrate, but it is clear that the catalyst has a significant capacity in addition to the nongassing capacity already identified. It appears that this additional capacity is at least three times the nongassing capacity. The stoichiometric trapping limit for the $73.9 \mathrm{wt} \%$ alumina in the catalyst is $0.83 \mathrm{~g} \mathrm{~F}_{2} / \mathrm{g}$ catalyst. Finally, we can report that both the catalyst treated at $500^{\circ} \mathrm{C}$ and the untreated catalyst produced a steady pressure rise immediately upon exposure to fluorine flow, as shown in Fig. 4. Catalyst prepared or treated in this manner will be ineffective as a nongassing getter.

The results for $\mathrm{NaI}$ consist of two trials conducted under the previous slow-flow conditions $\left(0.35 \mathrm{sccm} \mathrm{F}_{2}\right)$ for (a) $\mathrm{NaI}$ dried in a vacuum oven at $145^{\circ} \mathrm{C}$ for $48 \mathrm{~h}$ and thereafter handled in air, and (b) dried $\mathrm{NaI}$ further treated by heating to $500^{\circ} \mathrm{C}$ in a helium purge for $24 \mathrm{~h}$. The material treated at $500^{\circ} \mathrm{C}$ caked and sintered into a coherent clump, while the dried material retained its free-flowing character. Despite these apparent differences, both materials trapped fluorine without significant pressure accumulation until the stoichiometric limit for NaF formation was reached, as shown in Figs. 5 and 6. The results for the unsintered material were more regular and led to a clearer explanation of the reaction history. From Fig. 6, it is clear that the unsintered material developed very little retained gas pressure until almost all of the $\mathrm{NaI}$ had been converted to $\mathrm{NaF}$. The small slope in this initial period was not much greater than that associated with the potential for unreactive impurities in the fluorine feed. Thereafter, the pressure increase was consistent with $\mathrm{IF}_{5}$ accumulation from the reaction of $\mathrm{I}_{2}$ with $\mathrm{F}_{2}$.

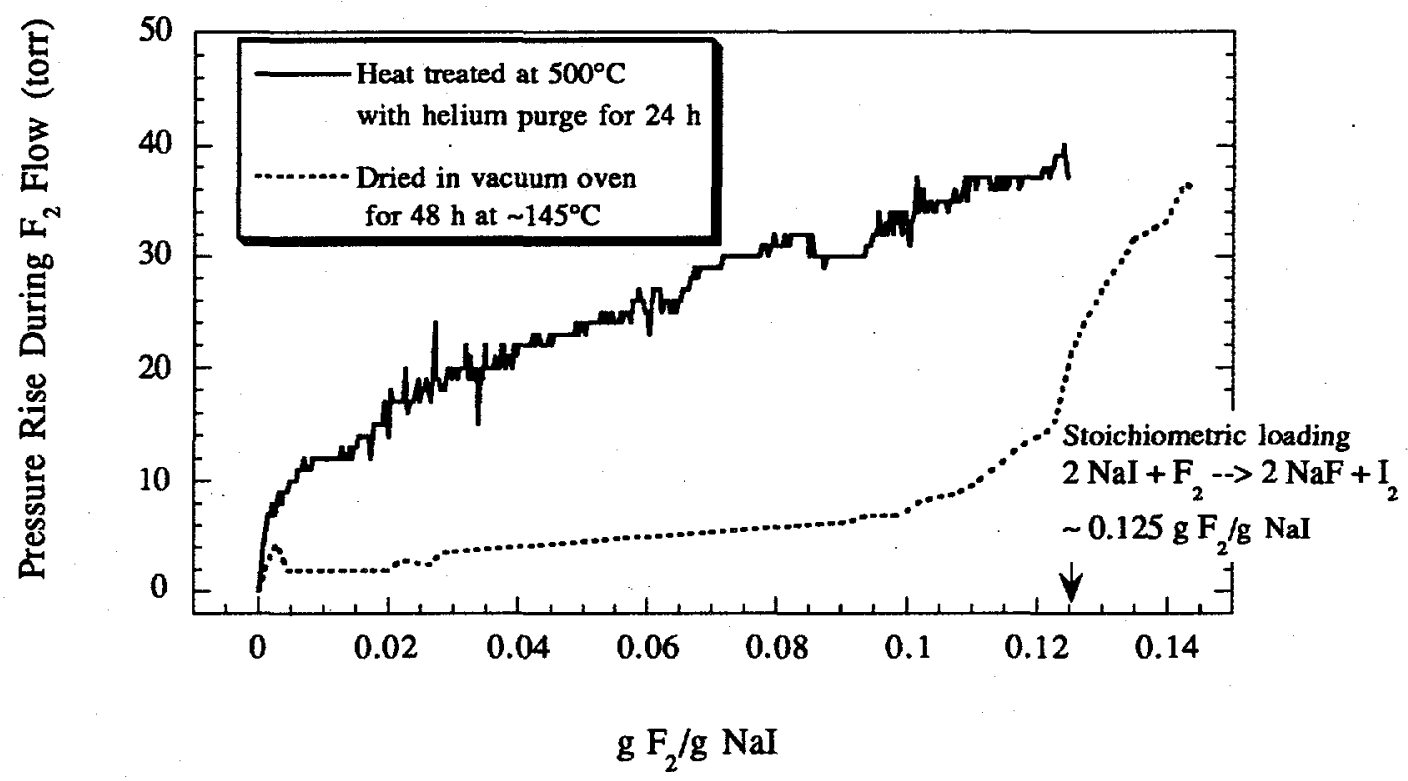

Fig. 5. Fluorine-trapping loading curve for $\mathrm{NaI} . \mathrm{F}_{2}$ flow $=0.35 \mathrm{sccm} ; 8.85-\mathrm{g} \mathrm{NaI}$ charge 


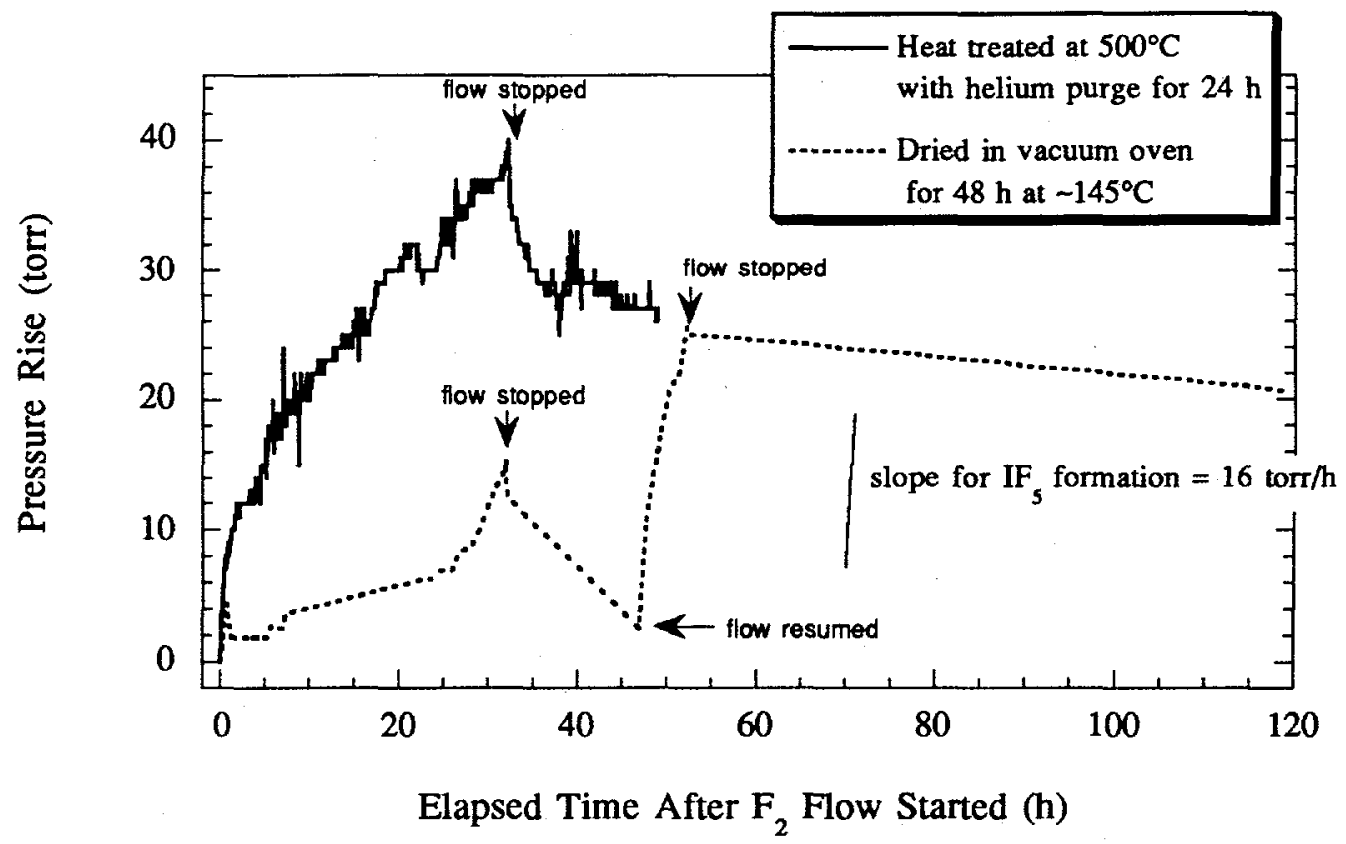

Fig. 6. Fluorine-trapping pressure history for $\mathrm{NaI} . \mathrm{F}_{2}$ flow $=0.35 \mathrm{sccm}$; 8.85-g NaI charge

The results for the sintered $\mathrm{NaI}$, although less clear, are consistent with a gradual and erratic buildup of small amounts of $\mathrm{F}_{2}$ and $\mathrm{IF}_{5}$ due to the poorer kinetics associated with the reaction of a sintered material. While this performance is clearly inferior to that of the unsintered material, it is not necessarily significant for the intended application because the pressure rise is still quite small, and also because the experimental fluorine delivery rate corresponds to a trapping flux ( $\mathrm{g} \mathrm{F}_{2} / \mathrm{g}$ agent/s) that is significantly higher than that of the probable storage condition. The stainless steel interior of the reaction chamber showed no evidence of corrosion after the NaI trials; however, the copper gasket was attacked and thin flakes of copper-containing material were collected for analysis. $\mathrm{X}$-ray diffraction was used to identify $\mathrm{CuI}$ in this corrosion product. It is almost certain that this material formed when $\mathrm{IF}_{5}$ (or some other interhalogen) attacked the copper seal. $\mathrm{IF}_{5}$ itself is a powerful corrosive agent and, because of its moderate vapor pressure (20 torr at room temperature), can condense and accelerate localized corrosion.

\subsection{OTHER SYSTEMS TESTED}

A number of other agents were tested that rapidly passivated or had other performance characteristics that permitted us to rapidly screen them from the list of candidate materials. These agents fell into three categories: (a) an additional iodide salt 
(KI), (b) "reactive" metals ( $\mathrm{Ca}, \mathrm{Sb}$, and $\mathrm{FeSb}$ ), and (c) sulfide salts (NiS, $\mathrm{ZnS}, \mathrm{Na}_{2} \mathrm{~S}$, and $\mathrm{CaS}$ ). An additional iodide, $\mathrm{KI}$, was tested because it is less hygroscopic than $\mathrm{NaI}$ and because literature reports suggested that it would be very effective [7]. Our results show that it is significantly less effective than $\mathrm{NaI}$ as a fluorine getter. The pressure history for slow-flow trials with KI, shown in Fig. 7, exhibits an initial horizontal region followed by a rapid breakthrough to a pressure rise consistent with fluorine accumulation ("limiting slope" indicated). The fluorine trapping capacity associated with this horizontal region is only $15 \%$ of the stoichiometric limit for $\mathrm{KF}$ formation and is roughly seven times less than that measured for $\mathrm{NaI}$.

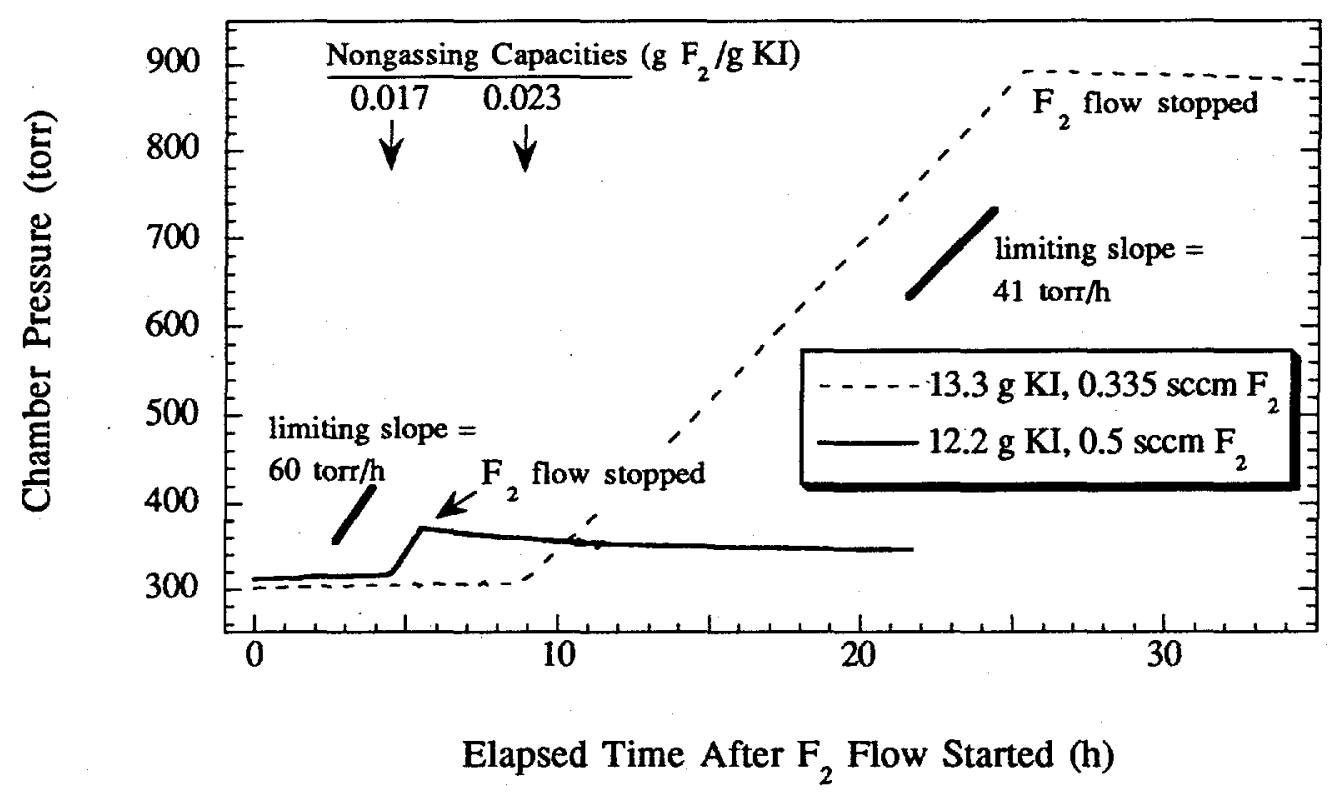

Fig. 7. Fluorine-trapping pressure history for KI.

The response of the "reactive" metals ( $\mathrm{Sb}, \mathrm{FeSb}$, and $\mathrm{Ca}$ ) is typified by the pressure history for the FeSb trial displayed in Fig. 8. The fluorine pressure over these materials was only marginally diminished by reaction with the metal (rapid passivation), and the decrease of accumulated fluorine after flow had been discontinued was extremely slow. The pressure histories for $\mathrm{Sb}$ and $\mathrm{FeSb}$ were almost identical, and the basic behavior of $\mathrm{Ca}$ was the same. These materials might have adequate kinetics for the very slow fluorine fluxes that will be associated with salt storage, but a great deal of experimental effort would be required to prove this; thus, this avenue was discontinued.

The response of the sulfide salt to fluorine is interesting because two classes of behavior are evident, as is demonstrated in Fig. $9 . \mathrm{ZnS}, \mathrm{NiS}$, and $\mathrm{Na}_{2} \mathrm{~S}$ passivate rapidly, 


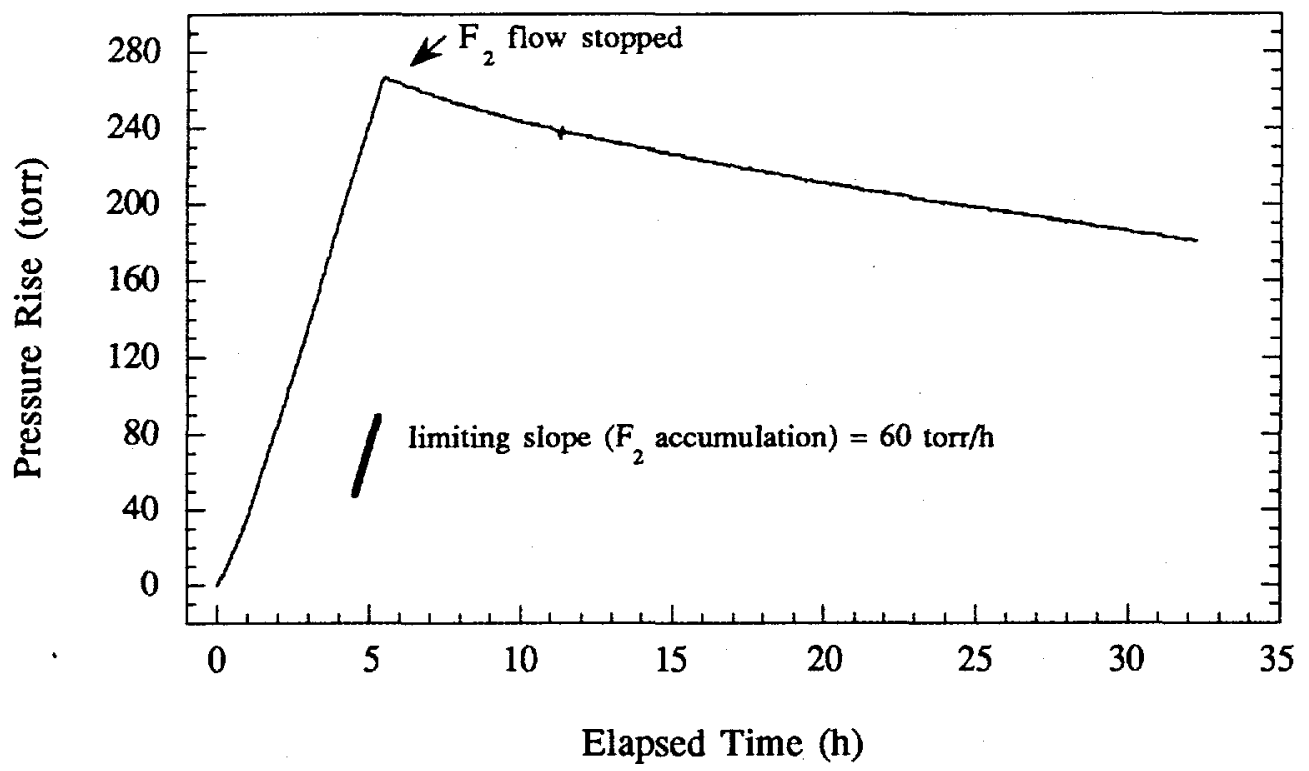

Fig. 8. Fluorine-trapping pressure history for FeSb. $F_{2}$ flow $=0.5 \mathrm{sccm}$



Elapsed time (h)

Fig. 9. Fluorine-trapping pressure history for sulfide salts. $F_{2}$ flow $=0.5 \mathrm{sccm}$ 
with an immediate accumulation of $F_{2}$ above the solids and the formation of only a small amount of metal fluoride. However, $\mathrm{CaS}$ appears to react completely to form a mixture of $\mathrm{CaF}_{2}$ and volatile sulfur fluorides (mainly $\mathrm{SF}_{6}$ ). The reduced rate of pressure rise for the $\mathrm{CaS}$ test is consistent with the predominance of $\mathrm{SF}_{6}$ as a reaction product. If only a reduced level of pressure rise was considered sufficient, then $\mathrm{CaS}$ or sulfur itself might be reconsidered as a trapping agent because of practical advantages. This avenue was not pursued because the present goal is to completely eliminate the potential for accumulating significant gas pressure in the storage containers.

\section{DISCUSSION}

This section compares the performance of the successful candidates and discusses any special characteristics or unresolved issues that can influence implementation of a particular trapping strategy. The simplest basis for comparing the candidates is to contrast the trapping material requirements for (a) sealed interim storage and (b) vented long-term disposal. These values are compiled in Table 5 and are based on the fluorine generation predictions and the trapping capacities measured or referenced in this report. The basis for these comparisons is a standard package that contains one-sixth of the entire fuel salt.

Table 5. Trapping-agent requirements for interim storage and long-term disposal of the MSRE fuel salt: $16.6 \%$ basis $^{a}$

\begin{tabular}{lccccc}
\hline & & & & \multicolumn{2}{c}{$\begin{array}{c}\text { Trapping agent volume } \\
\text { per tank }(\mathrm{L})\end{array}$} \\
\cline { 5 - 6 } $\begin{array}{c}\text { Trapping } \\
\text { agent }\end{array}$ & $\begin{array}{c}\text { Bulk } \\
\text { density } \\
(\mathrm{kg} / \mathrm{L})\end{array}$ & $\begin{array}{c}\text { Nongassing } \\
\text { trapping capacity } \\
\left(\mathrm{g} \mathrm{F}_{2} / \mathrm{g} \text { agent }\right)\end{array}$ & $\begin{array}{c}\text { Total trapping } \\
\text { capacity } \\
\left(\mathrm{g} \mathrm{F}_{2} / \mathrm{g} \text { agent }\right)\end{array}$ & $\begin{array}{c}\text { Interim } \\
\text { storage }\end{array}$ & Disposal \\
\hline Charcoal $^{b}$ & 0.44 & 0.61 & 0.61 & 2.0 & 39 \\
HTC $600^{n}$ & 0.81 & 0.075 & $>0.3$ & 8.9 & $<43$ \\
NaI $^{c}$ & 1.83 & 0.125 & 0.125 & 2.4 & 45 \\
Alumina $^{d}$ & 0.67 & & $>0.28$ & & $<55$ \\
\hline
\end{tabular}

${ }^{a}$ Six containers, $540 \mathrm{~g} \mathrm{~F}_{2}$ interim trapping required; $10.3 \mathrm{~kg} \mathrm{~F}_{2}$ trapping required for disposal.

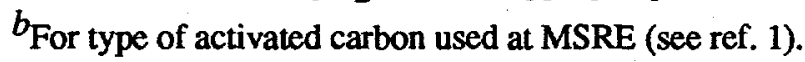

$c_{\text {Packing density of } 50 \% \text { assumed. }}$

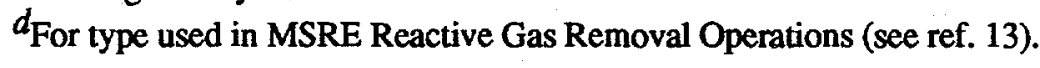


An entry has been added to Table 5 based on a projection of the amount of alumina that would be required for trapping fluorine during the long-term vented storage. It was assumed that only $25 \%$ of the theoretical alumina trapping capacity is effective. This estimate is based upon previous high-temperature fixed-bed trapping experience, where only about $50 \%$ of the alumina was rapidly consumed $[13]$, and the demonstrated $25 \%$ utilization of the HTC 600 alumina substrate. While the real situation is considerably more complicated, $25 \%$ utilization appears to be a useful lower bound for this comparison. This projection was added to the candidate list because it may be desirable to consider a simplified long-term disposal trapping strategy, with the vented gas being routed through an external trap containing an innocuous trapping agent such as alumina.

The volumes of trapping agent required for sealed storage with no gas generation are very small - only about $2 \mathrm{~L}$ for charcoal or $\mathrm{NaI}$ and about $9 \mathrm{~L}$ for the nickel catalyst. The nearly identical volumes of agent required for long-term vented disposal are even more surprising. All of the trapping agents, regardless of whether they generate some gas or not, occupy about $40 \mathrm{~L}$ in the disposal package. None of these trapping capacities are impractical, and the volumetric requirements for the various options are roughly equivalent. It is clear that qualitative trapping-agent characteristics are more important than simple trapping capacity. These characteristics are summarized in Table 6 and govern the most important implementation issues.

Table 6. Important characteristics of fluorine trapping agents

\begin{tabular}{|c|c|c|}
\hline Trapping agent & Characteristic & Global issues \\
\hline Charcoal & $\begin{array}{l}\text { Forms potentially explosive } \\
C_{x} F\end{array}$ & $\begin{array}{l}\text { Can the agent be added } \\
\text { before the salt is loaded? }\end{array}$ \\
\hline HTC 600 & $\begin{array}{l}\text { Requires regeneration; } \\
\text { air sensitive; } \\
\text { loses activity at } \mathrm{T}>300^{\circ} \mathrm{C}\end{array}$ & $\begin{array}{l}\text { Is the agent added to the } \\
\text { tank internals, or to the } \\
\text { external piping? }\end{array}$ \\
\hline $\mathrm{NaI}$ & $\mathrm{I}_{2}$ disposition; $\mathrm{IF}_{5}$ formation & \\
\hline
\end{tabular}

The only real issue that inhibits the use of charcoal (or activated carbon) involves the reluctance to revisit the safety considerations regarding the explosive potential of partially fluorinated charcoal. It has been shown that temperatures in excess of $100^{\circ} \mathrm{C}$ are required to initiate a deflagration event $[1]$, and it is very unlikely that temperatures this high would occur during normal storage conditions. It may be possible to separate the safety requirements that govern interim storage from those associated with long-term 
disposal if the charcoal can be removed as an external cartridge before configuration for the vented condition required by WIPP. There are no other scientific or implementation barriers, and, except for the $\mathrm{C}_{\mathrm{x}} \mathrm{F}$ issue, use of charcoal is undoubtedly the simplest trapping option.

There are a number of issues that complicate the trapping of fluorine with HTC 600 nickel catalyst. First, and most important, is the requirement that activated material be handled in an inert atmosphere. The most practical way to meet this requirement is to activate the catalyst in place - after the catalyst has been added (or connected) to the storage tank (but not necessarily with the salt present). Because the catalyst sinters and loses activity at temperatures above $300^{\circ} \mathrm{C}$, this agent must be thermally isolated from the molten salt. Adding the agent after the receiver vessel is full of highly radioactive salt is possible, but highly undesirable. The final complication occurs when the receiver is to be vented and a controlled exposure to oxygen is required to avoid "burning" the active portion of the catalyst. While all of these requirements can be met by a proper system design, the complexity of such a design is certain to add a significant cost.

Sodium iodide has none of the air-sensitivity or explosion potential complications of the previously discussed candidates, but there are some concerns about corrosion (potential for $\mathrm{IF}_{5}$ ) and iodine disposition that need to be addressed. The formation of corrosive interhalogens can be avoided by maintaining an excess of NaI. No significant inventory of $\mathrm{IF}_{5}$ will appear until almost all of the $\mathrm{NaI}$ was converted to fluoride. It is desirable, but not absolutely necessary, to avoid the sintering of this material by exposure to high temperatures. An excess of unsintered material will maintain extremely low $F_{2}$ and $\mathrm{IF}_{5}$ levels in the storage vessel.

Almost all of the $\mathrm{I}_{2}$ formed during trapping is retained as crystals attached to the $\mathrm{NaI} / \mathrm{NaF}$ matrix. Only the minute vapor pressure of $\mathrm{I}_{2}(\mathrm{~s})$ (i.e., 0.3 torr at $20^{\circ} \mathrm{C}$ ) normally exists in the gas space above the solid, and supersaturations above 200 torr are almost never exceeded [14]. The presence of $I_{2}$ is not an issue for the interim sealed-storage period, since $\mathrm{I}_{2}$ does not challenge the integrity of the storage vessel. However, final disposition of this material may require that the vented disposal system be equipped to isolate the inventory of $I_{2}$ solid that will otherwise volatilize. The use of conventional dry-trapping agents developed for nuclear power and reprocessing plants [15] was considered. Silver-substituted zeolites and other inorganic matrices provide for irreversible loadings of no more than $0.5 \mathrm{~g} \mathrm{I}_{2} / \mathrm{g}$ agent, and no more than about $0.3 \mathrm{~g} \mathrm{I}_{2} / \mathrm{g}$ agent should be expected in the absence of high-humidity conditions [15]. Even under these favorable conditions, the volume of trapping agent required for one salt receiver is 
large ( $400 \mathrm{~L}$ for $0.3-\mathrm{g} \mathrm{I}_{2} / \mathrm{g}$ agent capacity and $0.6-\mathrm{g} / \mathrm{mL}$ packing density of a typical zeolite). Some preliminary tests with $\mathrm{FeSb}$ indicate that higher capacities $\left(\sim 2 \mathrm{~g} \mathrm{I}_{2} / \mathrm{g}\right.$ agent) can be expected with this material, but the suitability of the reaction products for long-term storage has not been established. Further work is needed to fully explore this option.

Because the requirements for interim storage and final disposition are different in both degree (e.g., amount of trapping agent required) and kind (e.g., gastight vs vented, acceptance criteria), consideration should be given to an approach that is both flexible and easily implemented. Various vessel/trapping-agent configurations provide different degrees of flexibility and ease of implementation, as well as different levels of costs and complexity. For the purposes of this discussion, we define the two basic configurations depicted in Fig. 10: (a) direct contact and (b) external canisters. The direct-contact option is conceptually the simplest, but it is not the automatic choice because no non-gasgenerating trapping agent used in this fashion is certain to be approved for the long-term disposal option. All of the candidates - activated carbon, HTC 600 nickel catalyst, and $\mathrm{NaI}$ - have unresolved issues (previously discussed) that make this simplest of approaches open to some question.

The most useful versions of the external-canister approach appear to be those shown in Fig. 10. Either a series or a parallel piping arrangement can be used, as shown in options (a) and (b). For the case of $\mathrm{NaI}$ as the nongassing agent, the parallel option may be preferred because isolation of this agent during vented storage would prevent formation of $\mathrm{IF}_{5}$ (depending on the amount of $\mathrm{NaI}$ present) and ensure that the iodine formed during the previous period of interim storage is completely contained. This option may also be desirable for the activated-carbon case because of the need to isolate or remove the fluorinated charcoal prior to final disposal. Numerous additional implementation details derive from these basic configurational choices. The details cannot be dealt with concisely in this report. The purpose of this discussion is to supply the basic information required to make the trade-offs required to identify the optimum fluorine-trapping design for the disposition of the MSRE fuel salt. 

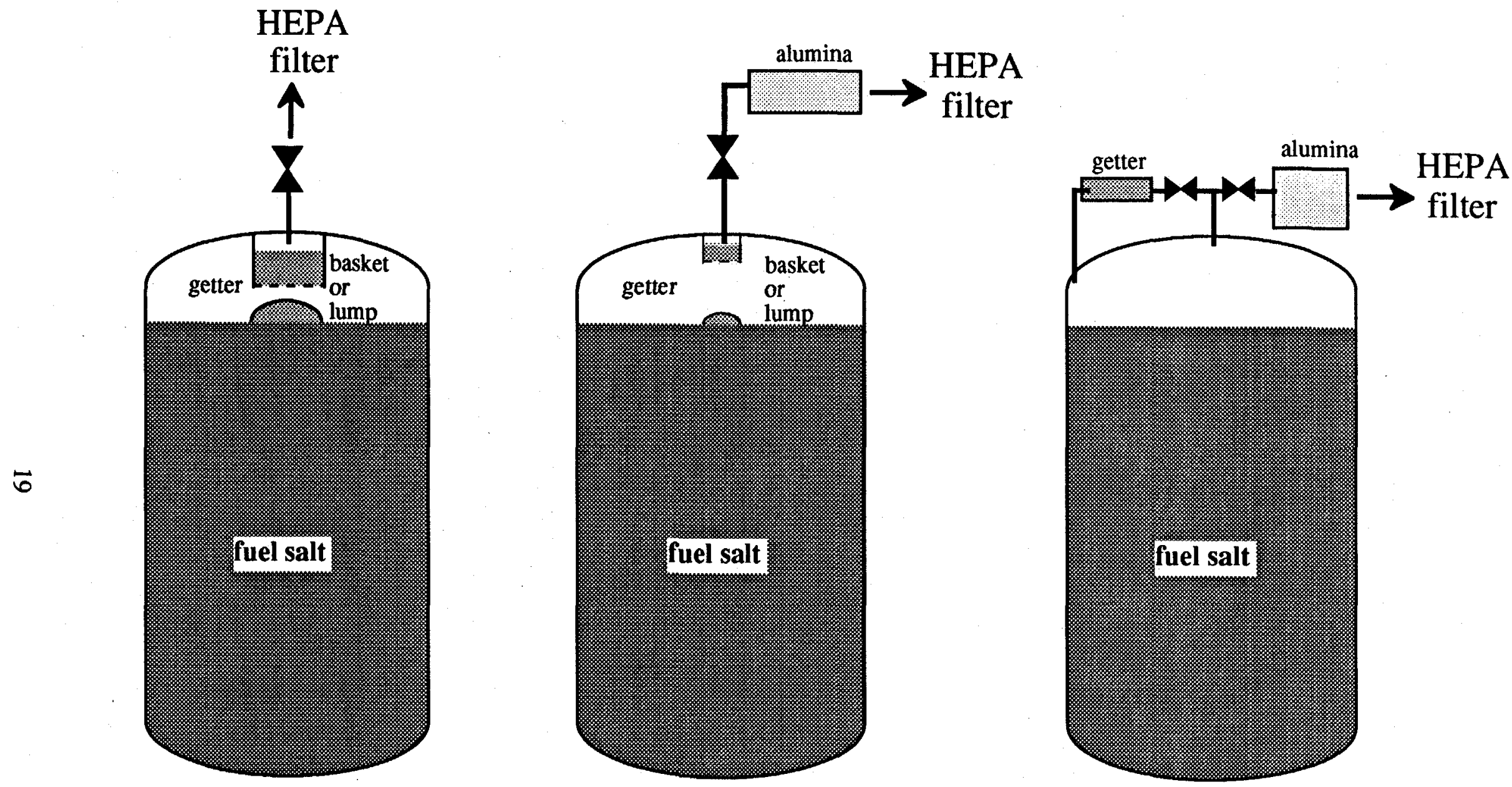

(a)

(b)

Direct-Contact Option

External-Canister Option

Fig. 10. Basic trapping configurations. 


\section{6.' REFERENCES}

1. R. L. Farrar and E. J. Barber, Some Considerations in the Handling of Fluorine and Chlorine Fluorides, K/ET-252, Oak Ridge Gaseous Diffusion Plant (July 1979).

2. G. D. Del Cul et al., Some Investigations of the Reaction of Activated Charcoal with Fluorine and Uranium Hexafluoride, ORNL/TM-13052, Oak Ridge National Laboratory, September 1988, pp. 64-66.

3. M. G. Otey and C. K. Bayne, Fixed Bed Trapping for Gaseous Fluoride Effluent Control, KY-705, Paducah Gaseous Diffusion Plant, June 1980.

4. M. H., Moisson, Ann. Chim. Phys. 6(24), 224-82 (1891).

5. M. G. Fontana, Ind. Eng. Chem. 39(3), 917 (1947).

6. E. Lingau, Werkstoffe Korrosion 7, 634 (1956).

7 M. H., Moisson, Ann. Chim. Phys. 6(24), 258 (1891).

8. R. J. Meyer, Gmelin Handbuch der Anorganische Chemie, vol. 8, p. 186.

9. D. F. Williams, G. D. Del Cul, and L. M. Toth, A Descriptive Model of the Molten Salt Reactor After Shutdown: Review of FY 1995 Progress, ORNL/TM-13142, Oak Ridge National Laboratory, January 1996, pp. 64-66.

10. L. M. Toth and L. K. Felker, "Fluorine Generation by Gamma Radiolysis of a Fluoride Salt Mixture," Radiat. Eff. Def. Solids 112, 201-10 (1990).

11. F. J. Peretz, ORNL Chemical Technology Division, personal communication, July 1998.

12. R. M Szozda, ORNL, personal communication, March 10, 1999.

13. J. C. Rudolph et al., Laboratory Tests in Support of MSRE Reactive Gas Removal, ORNL/TM-13191, Oak Ridge National Laboratory, July 1997.

14. F. Becher, Z. Phys. Chem. 78, 56 (1912).

15. D. W. Holladay, A Literature Survey: Methods for the Removal of Iodine Species from Off-Gases and Liquid Waste Streams of Nuclear Power and Nuclear Fuel Reprocessing Plants, with Emphasis on Solid Sorbents, ORNL/TM-6350, Oak Ridge National Laboratory, January 1979. 
ORNL/TM-13770

\section{INTERNAL DISTRIBUTION}

1. R. R. Aigner

2. J. Brynestad

3. M. E. Buchanan

4. S. N. Burman

5. J. Caja

6. W. A. Camp

7. R. A. Campbell

8. S. G. Coffey

9. R. M. Counce

10. A. G. Croff

11. S. Dai

12. G. D. Del Cul

13. J. R. DiStefano

14. R. L. Faulkner

15. U. Gat

16. L. L. Gilpin

17. Q. G. Grindstaff

18. C. L. Hedrick

19. A. S. Icenhour

20. R. T. Jubin

21. J. R. Keiser

22. R. A. Kite
23. L. E. McNeese

24. T. C. Morelock

25. B. D. Patton

26. F. J. Peretz

27. A. H. Primm

28. D. W. Ramey

29. J. E. Rushton

30. D. W. Simmons

31. N. R. Smyrl

32. B. B. Spencer

33. R. M. Szozda

34. L. M. Toth

35. L. D. Trowbridge

36. D. H. Vandergriff

37-41. D. F. Williams

42. J. P. Young

43. ER Document Management Center

44. Central Research Library

45. ORNL Laboratory Records - RC

46-47. ORNL Laboratory Records for OSTI

\section{EXTERNAL DISTRIBUTION}

48. Steve Cupps, Synetix USA/ICI, Two Transam Plaza Dr., Oakbrook Terrace IL 60181

49. G. R. Eidam, Bechtel Jacobs Company LLC, Building 7078-D, P.O. Box 2008 MS-6402, Oak Ridge, TN 37831-6402

50. R. C. Farr, Department of Energy, Building 7078, P.O. Box 2008 MS-6402, Oak Ridge, TN 37831-6402

51. J. R. Engel, 118 E. Morningside Drive, Oak Ridge, TN 37830

52. M. H. Haghighi, Bechtel Jacobs Company LLC, PO BOX 2008 MS-6427, Oak Ridge, TN 37831-6427

53. R. L. Jones, Paducah Gaseous Diffusion Plant, Bldg. C300, P.O. Box 1410, Paducah , KY 42002-1410

54. M. R. Jugan, Environmental Restoration, Department of Energy, Oak Ridge Operations, P.O. Box 2001, Oak Ridge, TN 37831

55. A. P. Kelsey, Bechtel Jacobs Company LLC, Building 7078-D, P.O. Box 2008 MS-6402, Oak Ridge, TN 37831-6402

56. C. S. Mims, Environmental Restoration, Department of Energy, Oak Ridge Operations, P.O. Box 2001, Oak Ridge, TN 37831 
57. L. P. Pugh, 2024 Cedar Lane, Kingston, TN 37763

58. R. G. Russell, Paducah Gaseous Diffusion Plant, Bldg. C710, P.O. Box 1410, Paducah, KY 42002-1410

59. A. J. Saraceno, Portsmouth Gaseous Diffusion Plant, Bldg. X710, P.O. Box 628, MS-2212, Portsmouth, OH 45661-2212

60. J. E. Shoemaker Jr., Portsmouth Gaseous Diffusion Plant, Bldg. X100, P.O. Box 628, MS-1223, Portsmouth, OH 45661-1223

61. R. E. Thoma, 119 Underwood Road, Oak Ridge, TN 37830

62. P. G. Wooldridge, Paducah Gaseous Diffusion Plant, Bldg. C710, P.O. Box 1410, Paducah, KY 42002-1410

63. R. G. Wymer, 188-A Outer Drive, Oak Ridge, TN 37830 